OPEN ACCESS

Edited by:

Masahiro Ito,

Toyo University, Japan

Reviewed by:

Masanori Toyofuku,

University of Tsukuba, Japan

Yosuke Tashiro,

Shizuoka University, Japan

*Correspondence:

Tatsuo Kurihara

kurihara@scl.kyoto-u.ac.jp

${ }^{\dagger}$ Present address:

Fumiaki Yokoyama

Bioanalytics Group, Department

of Biosystems Science

and Engineering, ETH Zurich, Basel,

Switzerland

Specialty section:

This article was submitted to

Extreme Microbiology,

a section of the journal

Frontiers in Microbiology

Received: 13 November 2020

Accepted: 29 January 2021

Published: 18 February 2021

Citation:

Yokoyama F, Imai T, Aoki W, Ueda M, Kawamoto J and Kurihara $T$ (2021) Identification of a Putative Sensor Protein Involved in Regulation of Vesicle Production by a Hypervesiculating Bacterium,

Shewanella vesiculosa HM13.

Front. Microbiol. 12:629023. doi: 10.3389/fmicb.2021.629023

\section{Identification of a Putative Sensor Protein Involved in Regulation of Vesicle Production by a Hypervesiculating Bacterium, Shewanella vesiculosa HM13}

\author{
Fumiaki Yokoyama1†, Tomoya Imai', Wataru Aoki ${ }^{3,4}$, Mitsuyoshi Ueda ${ }^{3,4}$, Jun Kawamoto' \\ and Tatsuo Kurihara ${ }^{1 *}$ \\ ${ }^{1}$ Institute for Chemical Research, Kyoto University, Uji, Japan, ${ }^{2}$ Research Institute for Sustainable Humanosphere, Kyoto \\ University, Uji, Japan, ${ }^{3}$ Division of Applied Life Sciences, Graduate School of Agriculture, Kyoto University, Kyoto, Japan, \\ ${ }^{4}$ Kyoto Integrated Science and Technology Bio-Analysis Center, Kyoto, Japan
}

Bacteria secrete and utilize nanoparticles, called extracellular membrane vesicles (EMVs), for survival in their growing environments. Therefore, the amount and components of EMVs should be tuned in response to the environment. However, how bacteria regulate vesiculation in response to the extracellular environment remains largely unknown. In this study, we identified a putative sensor protein, HM1275, involved in the induction of vesicle production at high lysine concentration in a hypervesiculating Gram-negative bacterium, Shewanella vesiculosa HM13. This protein was predicted to possess typical sensing and signaling domains of sensor proteins, such as methyl-accepting chemotaxis proteins. Comparison of vesicle production between the hm1275-disrupted mutant and the parent strain revealed that HM1275 is involved in lysine-induced hypervesiculation. Moreover, HM1275 has sequence similarity to a biofilm dispersion protein, BdlA, of Pseudomonas aeruginosa PAO1, and hm1275 disruption increased the amount of biofilm. Thus, this study showed that the induction of vesicle production and suppression of biofilm formation in response to lysine concentration are under the control of the same putative sensor protein.

Keywords: extracellular membrane vesicles, biofilm, Shewanella, cold-adapted bacterium, sensor protein

\section{INTRODUCTION}

Bacterial cells respond to extracellular environments, create multicellular communities, and communicate with others for survival in their growing environments. To communicate, they secrete and utilize nanoparticles, called extracellular membrane vesicles (EMVs) (Schwechheimer and Kuehn, 2015). Therefore, the amount and components of EMVs should be tuned in response to the environment (Orench-Rivera and Kuehn, 2016). EMVs are composed of various components, such as lipids, proteins, nucleic acids, lipopolysaccharides, and peptidoglycans (Bitto and Kaparakis-Liaskos, 2017). Major components of EMVs of Gram-negative bacteria are derived from the outer membrane and periplasm of the cells, while components of the inner membrane and cytoplasm are also found in EMVs from various bacterial species 
(Toyofuku et al., 2015; Jain and Pillai, 2017; Tan et al., 2018). Owing to the diversity of these components, EMVs have various physiological roles, being involved in biofilm formation, nutrient uptake, defense (acting as decoys against bacteriophages), and intercellular communication related to horizontal gene transfer and pathogenesis (Toyofuku et al., 2015). Moreover, EMVs have been applied to the development of vaccines and drug delivery systems (Jain and Pillai, 2017; Tan et al., 2018). Elucidation of the vesiculation mechanisms is required for the understanding of their physiology and the development of their applications. Although multiple mechanisms of vesicle production have been suggested to occur in various bacteria (Schwechheimer and Kuehn, 2015; Toyofuku et al., 2015), it remains largely unclear how bacteria regulate the production levels of EMVs in response to extracellular environments.

We previously isolated a bacterial strain suitable for studies of EMVs. This strain, Shewanella vesiculosa HM13, is a Gramnegative and cold-adapted bacterium that was isolated from horse mackerel intestines (Chen et al., 2020). Vesiculation by this bacterium has two unique features: higher vesicle production than other strains such as Escherichia coli and high purity and productivity of a single specific protein in EMVs; these characteristics make S. vesiculosa HM13 useful for elucidating the mechanisms of bacterial vesiculation and protein transport to EMVs (Chen et al., 2020; Guida et al., 2020; Kamasaka et al., 2020; Kawano et al., 2020).

In this study, we identified a putative sensor protein in S. vesiculosa HM13 EMVs that harbors sensory Per-Arnt-Sim (PAS) domains and a signaling domain of a methyl-accepting chemotaxis protein (MCP). This protein showed sequence similarity to a biofilm dispersion protein, BdlA, of Pseudomonas aeruginosa PAO1 (Morgan et al., 2006; Barraud et al., 2009; Petrova and Sauer, 2012). Gene disruption and quantification of EMVs and biofilm showed that this protein is involved in the sensing of lysine (Lys) in the extracellular environment to induce vesicle production and regulate biofilm formation.

\section{MATERIALS AND METHODS}

\section{Bacterial Strains and Culture Conditions}

The strains used in this study are listed in Table 1. A coldadapted bacterium, S. vesiculosa HM13, was isolated from the intestines of horse mackerel, and a rifampicin-resistant mutant of this strain (HM13-Rif ${ }^{\mathrm{r}}$ ) was used as a parental strain (Chen et al., 2020). A mutant $(\Delta g s p D 2)$ lacking a protein required for the transport of a major EMV cargo protein, P49, was used to identify minor proteins included in EMVs (Chen et al., 2020). Another mutant lacking a putative sensor protein encoded by $h m 1275$ was prepared by gene disruption using a pKNOCK plasmid (Table 1). In brief, a linear fragment of pKNOCK, amplified with the primers pKNOCK-1 and -2 (Table 2), was fused with the internal fragment of $h m 1275$, amplified with the primers Dhm1275-1 and -2 (Table 2) using a NEBuilder HiFi DNA Assembly Kit (New England Biolabs, Ipswich, MA, United States) according to the manufacturer's instructions. S. vesiculosa HM13-Rif ${ }^{\mathrm{r}}$ was conjugated with E. coli
TABLE 1 | Bacterial strains and plasmids used in this study.

\begin{tabular}{|c|c|c|}
\hline $\begin{array}{l}\text { Strain or } \\
\text { plasmid }\end{array}$ & Description & References \\
\hline \multicolumn{3}{|l|}{ Strains } \\
\hline \multicolumn{3}{|l|}{ E. coli } \\
\hline S17-1/גpir & $\begin{array}{l}\text { E. coli S17-1 derivative, host for } \\
\text { pir-dependent plasmids }\end{array}$ & $\begin{array}{l}\text { Simon et al., } \\
1983\end{array}$ \\
\hline \multicolumn{3}{|c|}{ S. vesiculosa } \\
\hline HM13-Rifr & $\begin{array}{l}\text { Parental strain, rifampicin resistant mutant } \\
\text { of } S \text {. vesiculosa } \mathrm{HM} 13\end{array}$ & $\begin{array}{l}\text { Chen et al., } \\
2020\end{array}$ \\
\hline$\Delta g s p D 2$ & $\begin{array}{l}\text { hm3349-disrupted mutant } \\
\text { (hm3349:pKNOCK) of HM13-Rifr }\end{array}$ & $\begin{array}{l}\text { Chen et al., } \\
2020\end{array}$ \\
\hline$\Delta h m 1275$ & $\begin{array}{l}\text { hm1275-disrupted mutant } \\
\text { (hm1275:pKNOCK) of HM13-Rifr }\end{array}$ & This work \\
\hline \multicolumn{3}{|l|}{ Plasmids } \\
\hline pKNOCK & $\mathrm{Km}^{\mathrm{r}}$ & Alexeyev, 1999 \\
\hline pJRD-Cm ${ }^{r}$ & $\begin{array}{l}\mathrm{Cm}^{r} \text {; A pJRD215 derivative with } \mathrm{Cm}^{\mathrm{r}} \\
\text { instead of } \mathrm{Km}^{\mathrm{r}}\end{array}$ & $\begin{array}{l}\text { Toyotake et al., } \\
2018\end{array}$ \\
\hline phm1275 & $\begin{array}{l}\mathrm{Cm}^{r} \text {; A pJRD-Cm }{ }^{r} \text { derivative containing } \\
h m 1275 \text { at the Mlul-Spel site }\end{array}$ & This work \\
\hline
\end{tabular}

TABLE 2 | Primers used in this study.

\begin{tabular}{|c|c|c|}
\hline Primers & Sequence & Target gene \\
\hline pKNOCK-1 & GATATCAAGCTTATCGATACCG & pKNOCK \\
\hline pKNOCK-2 & CACTAGTTCTAGAGCGGC & As above \\
\hline pJRD-Cm ${ }^{r}-1$ & TAGTATAGTCTATAGTCCGTGG & pJRD-Cm ${ }^{r}$ \\
\hline pJRD-Cm ${ }^{r}-2$ & CGTAATCCATGGATCAAGAG & As above \\
\hline Dhm1275-1 & $\frac{\text { CGGCCGCTCTAGAACTAGTG }}{\text { GCGCCAGAGGAACAGCTC }}$ & $h m 1275$ \\
\hline Dhm1275-2 & $\frac{\text { GTATCGATAAGCTTGATA }}{\text { CAATCCTTGTAGTGCTTGTT }}$ & As above \\
\hline Chm1275-1 & $\frac{\text { CTCTTGATCCATGGATTACG }}{\text { GTITAATGAGTAATCTAACTTCCAC }}$ & As above \\
\hline Chm1275-2 & $\frac{\text { CCACGGACTATAGACTATACTA }}{\text { TTAAGTATTGAGTTGATTGGCAAA }}$ & As above \\
\hline
\end{tabular}

The sequences overlapping those of the vectors are underlined.

S17-1/ $\lambda$ pir transformed with the plasmid and then selected on a $1.5 \%$ lysogeny broth (LB) agar plate with rifampicin (Rif, $50 \mu \mathrm{g} / \mathrm{mL}$ ) and kanamycin $(\mathrm{Km}, 50 \mu \mathrm{g} / \mathrm{mL})$ to obtain the mutant $\Delta h m 1275$. The HM13-Rif ${ }^{\mathrm{r}}$ strain and all mutants were subcultured from seed culture using fresh media (1:100 dilution rate) without antibiotics. For the complementation assay of $h m 1275$, an empty vector-introduced strain, $\Delta h m 1275 / \mathrm{p}$, and the complemented strain, $\Delta h m 1275 / \mathrm{phm} 1275$, were prepared as described below in the section "Construction of Complemented Strain." After cultivation, the mutants and empty vectorintroduced/complemented strains were plated onto a $1.5 \% \mathrm{LB}$ agar plate with Rif $(50 \mu \mathrm{g} / \mathrm{mL})$ and $\mathrm{Km}(50 \mu \mathrm{g} / \mathrm{mL})$, or with Rif, $\mathrm{Km}$, and chloramphenicol ( $\mathrm{Cm}, 30 \mu \mathrm{g} / \mathrm{mL})$, respectively, to confirm the maintenance of the plasmid and the plasmid-derived sequence in the genome.

To investigate the effects of the growth environment on vesiculation, three media were used: LB, modified DSMZ medium 79 (M79 medium) (Papa et al., 2006), and Bacto Marine Broth (MB) (Difco Laboratories, Detroit, MI, United States). The M79 
medium contained $1 \mathrm{~g} / \mathrm{L} \mathrm{KH}_{2} \mathrm{PO}_{4}, 1 \mathrm{~g} / \mathrm{L} \mathrm{NH}_{4} \mathrm{NO}_{3}, 10 \mathrm{~g} / \mathrm{L} \mathrm{NaCl}$, $0.2 \mathrm{~g} / \mathrm{L} \mathrm{MgSO}_{4} .7 \mathrm{H}_{2} \mathrm{O}, 10 \mathrm{mg} / \mathrm{L} \mathrm{FeSO}_{4}, 10 \mathrm{mg} / \mathrm{L} \mathrm{CaCl} 2.2 \mathrm{H}_{2} \mathrm{O}$, and $0.5 \% \mathrm{w} / \mathrm{v}$ casamino acid (CA). M79 medium supplemented with additional CA or Lys (hereafter, M79 + CA or M79 + Lys, respectively) was also used to investigate the effects of amino acids on vesiculation. HM13-Rif ${ }^{\mathrm{r}}$ and $\Delta h m 1275$ were grown at $18^{\circ} \mathrm{C}$ and $180 \mathrm{rpm}$ in a Bio Shaker BR-43FL (TAITEC CORPORATION, Saitama, Japan) until the cultures reached the early stationary phase. The optical density at $600 \mathrm{~nm}\left(\mathrm{OD}_{600}\right)$ was measured with a UV-visible spectrophotometer (UV-2450, Shimadzu, Kyoto, Japan). The growth curve was obtained using a rocking incubator TVS062CA (ADVANTEC, Tokyo, Japan) at $18^{\circ} \mathrm{C}$ and $70 \mathrm{rpm}$.

\section{Construction of Complemented Strain}

A DNA fragment including the estimated promoter region and coding region of $h m 1275$ was obtained by PCR with Q5 High-Fidelity DNA Polymerase (New England Biolabs) using S. vesiculosa HM13 genomic DNA as a template and the primers Chm1275-1 and -2 (Table 2). The resulting DNA fragment and linearized pJRD-Cm ${ }^{r}$ (Toyotake et al., 2018), prepared by PCR with the primers pJRD-Cm ${ }^{r}-1$ and -2 (Table 2), were fused to construct pJRD-Cm ${ }^{\mathrm{r}} / h m 1275$ using a NEBuilder HiFi DNA Assembly Kit, according to the manufacturer's instructions. $\Delta h m 1275$ was conjugated with E. coli S17-1/ $\lambda$ pir, transformed with $\mathrm{pJRD}-\mathrm{Cm}^{\mathrm{r}} / \mathrm{hm} 1275$ or the empty vector $\mathrm{pJRD}$ $\mathrm{Cm}^{\mathrm{r}}$, and then selected on a $1.5 \% \mathrm{LB}$ agar plate with Rif $(50 \mu \mathrm{g} / \mathrm{mL}), \mathrm{Km}(50 \mu \mathrm{g} / \mathrm{mL})$, and $\mathrm{Cm}(30 \mu \mathrm{g} / \mathrm{mL})$ to obtain a complemented strain and the empty vector-introduced strain, $\Delta h m 1275 / \mathrm{phm1275}$ and $\Delta h m 1275 / \mathrm{p}$, respectively.

\section{Isolation of EMVs by Ultracentrifugation}

EMVs from S. vesiculosa HM13 were collected from cultures at the early stationary phase, unless otherwise stated, according to a previously described method (Yokoyama et al., 2017) with slight modifications. In brief, the cells were pelleted by centrifugation at $6,800 \times g$ and $4^{\circ} \mathrm{C}$ for $10 \mathrm{~min}$. The supernatant was centrifuged at $13,000 \times g$ and $4^{\circ} \mathrm{C}$ for $15 \mathrm{~min}$ to remove the remaining bacterial cells. The supernatant was filtered through a $0.45-\mu \mathrm{m}$ pore polyethersulfone (PES) filter to remove the remaining debris. EMVs were obtained by ultracentrifugation from $4 \mathrm{~mL}$ of filtrate at $100,000 \times g$ (average centrifugal force) and $4^{\circ} \mathrm{C}$ for $2 \mathrm{~h}$ with an Optimax centrifuge (Beckman Coulter, Brea, CA, United States). The pellets were resuspended in $400 \mu \mathrm{L}$ of Dulbecco's phosphatebuffered saline (DPBS) (Manning and Kuehn, 2011) and used as EMVs in the following experiments. The post-ultracentrifuged supernatant without EMVs was kept as a post-vesicle fraction (PVF) for subsequent experiments.

\section{Vesicle Quantification by Lipid Staining}

Lipids in the EMV fractions were quantified with a lipophilic fluorescent molecule, FM4-64 (Molecular Probes/Thermo Fisher Scientific, Waltham, MA, United States). The fluorescence intensities were divided by the $\mathrm{OD}_{600}$ values of the cultures for normalization to quantify vesicle production, according to previously described methods (Yokoyama et al., 2017). To examine the effects of Lys concentration on vesicle production,
EMVs of HM13-Rif ${ }^{\mathrm{r}}$, statically cultured at $18^{\circ} \mathrm{C}$ for 3 days in $5 \mathrm{~mL}$ of M79 media with different Lys concentrations, were quantified as described above. The maximum concentration of Lys in this study $(2.6 \mathrm{~g} / \mathrm{L})$ is supposed to be physiologically relevant and comparable to the one found in the intestine of horse mackerel, the host of S. vesiculosa HM13, which consumes krill as its main diet (Huntley et al., 1994; Chen et al., 2009; Kolmakova and Kolmakov, 2019).

\section{Protein Identification by Peptide Mass Fingerprinting}

Proteins associated with EMVs $(600 \mu \mathrm{g})$ of $\Delta g s p D 2$ aerobically cultured in LB were identified by two-dimensional polyacrylamide gel electrophoresis (2D-PAGE) and peptide mass fingerprinting, according to previously described methods (Park et al., 2012) with slight modifications. The peptide mass spectra of each protein spot were subjected to MASCOT search (Matrix Science, London, United Kingdom) against the S. vesiculosa HM13 protein database. The identified proteins were profiled using BLAST ${ }^{1}$ (Altschul et al., 1997) and HHpred² (Söding et al., 2005). The localizations of the identified proteins were predicted using PSORTb version 3.0.2 (Yu et al., 2010) and are listed in Table 3.

\section{Quantification of Biofilm by Crystal Violet Staining}

The cells attached to the solid surface were stained with crystal violet $(\mathrm{CV})$ to quantify the amount of biofilm, according to previously described methods (Thormann et al., 2004) with slight modifications. In brief, the cells were grown statically in $150 \mu \mathrm{L}$ of M79 medium with CA or amino acid supplementation in a 96-well U-bottom plate (Delta Lab, Barcelona, Spain) at the optimal growth temperature for HM13-Rif ${ }^{\mathrm{r}}\left(18^{\circ} \mathrm{C}\right)$ for 3 days. After cultivation, the floating cells were removed, and the remaining cells attached to the plate were washed twice with $170 \mu \mathrm{L}$ of water. After drying the plate at room temperature for approximately $5 \mathrm{~min}, 170 \mu \mathrm{L}$ of $0.1 \% \mathrm{CV}$ aq. was added to the wells and incubated at room temperature for $30 \mathrm{~min}$. After the staining solution was removed, the wells were washed twice with $300 \mu \mathrm{L}$ of water. Then, the cells were destained with $170 \mu \mathrm{L}$ of $95 \%$ ethanol (Nacalai Tesque, Kyoto, Japan) by incubation at room temperature for $30 \mathrm{~min}$. One hundred microliters of the destaining solution were applied to a 96-well flat-bottom plate (Delta Lab) to measure the absorbance at $570 \mathrm{~nm}$ with a plate reader (SpectraMax 190, Molecular Devices, San Jose, CA, United States).

\section{Biofilm Observation by Scanning Electron Microscopy}

To observe the fine structure of the biofilm formed at the air-liquid interface, the biofilm formed on a glass strip was subjected to scanning electron microscopy (SEM), according

\footnotetext{
${ }^{1}$ http://www.ncbi.nlm.nih.gov/blast

${ }^{2}$ https://toolkit.tuebingen.mpg.de/tools/hhpred

${ }^{3}$ http://www.psort.org/psortb/
} 
TABLE 3 | The identified proteins in EMVs from $\Delta g s p D 2$.

\begin{tabular}{|c|c|c|c|c|c|c|c|}
\hline No. ${ }^{a}$ & Gene & $\begin{array}{l}\text { Function of the protein predicted by its } \\
\text { sequence }\end{array}$ & $\begin{array}{l}\text { Calculated mass } \\
\text { (mass/Da) }\end{array}$ & Calculated pl & $E$-value ${ }^{\mathrm{b}}$ & Localization $^{c}$ & Accession \\
\hline 1 & $h m 67$ & Siderophore biosynthesis protein PvsD & 73,079 & 6.38 & $4.8 \times 10^{-2}$ & $\mathrm{IM}$ & LC533412 \\
\hline 2 & $h m 433$ & $50 S$ ribosomal protein $L$ & 20,230 & 9.38 & $4.2 \times 10^{-2}$ & C & LC533413 \\
\hline 3 & $h m 594$ & HDOD domain-containing protein & 30,072 & 5.14 & $3.6 \times 10^{-2}$ & C & LC533414 \\
\hline 4 & $h m 679$ & DNA-directed RNA polymerase omega subunit & 10,081 & 4.97 & $7.6 \times 10^{-3}$ & $\mathrm{C}$ & LC533415 \\
\hline 5 & $h m 841$ & Mechanosensitive ion channel family protein & 21,250 & 10.2 & $1.3 \times 10^{-2}$ & $\mathrm{IM}$ & LC533416 \\
\hline 6 & hm858 & Lysine-sensitive aspartokinase 3 & 50,020 & 5.51 & $4.0 \times 10^{-2}$ & $\mathrm{C}$ & LC533417 \\
\hline 7 & $h m 1275$ & Methyl-accepting chemotaxis protein & 49,116 & 5.99 & $3.3 \times 10^{-2}$ & $\mathrm{IM}$ & LC533418 \\
\hline 8 & $h m 1305$ & Zinc chelation protein SecC & 39,225 & 8.58 & $3.1 \times 10^{-2}$ & Not predictable & LC533419 \\
\hline 9 & $h m 1390$ & $\begin{array}{l}\text { Error-prone, lesion bypass DNA polymerase V } \\
\text { (UmuC) }\end{array}$ & 47,001 & 9.36 & $5.1 \times 10^{-2}$ & C & LC533420 \\
\hline 10 & $h m 1529$ & Hypothetical protein & 23,709 & 9.03 & $3.2 \times 10^{-4}$ & Not predictable & LC533421 \\
\hline 11 & hm2195 & $\begin{array}{l}\text { tRNA (carboxy-S-adenosyl-L-methionine) } \\
\text { synthase CmoA }\end{array}$ & 26,476 & 5.49 & $3.6 \times 10^{-2}$ & C & LC533422 \\
\hline 12 & $h m 2235$ & Glucose-1-phosphate adenylyltransferase & 46,828 & 6.28 & $4.5 \times 10^{-2}$ & Not predictable & LC533423 \\
\hline 13 & hm3132 & Pyruvate oxidase & 45,665 & 5.69 & $4.8 \times 10^{-2}$ & $\mathrm{IM}$ & LC533424 \\
\hline 14 & hm3337 & Hypothetical protein & 18,135 & 9.92 & $4.5 \times 10^{-2}$ & $\mathrm{IM}$ & LC533425 \\
\hline 15 & hm3779 & $\begin{array}{l}\text { RNA polymerase-binding protein DksA } \\
\text { (C4-type zinc finger protein) }\end{array}$ & 16,848 & 5.21 & $5.4 \times 10^{-2}$ & $\mathrm{C}$ & LC533426 \\
\hline
\end{tabular}

a Annotated spot numbers indicated in Figure 2.

$\mathrm{b}$ The E-value is the number of hits expected with a similar score by chance when searching the database with the amino acid sequence of each protein.

c The subcellular localization of each protein was predicted using a subcellular localization prediction tool, PSORTb version 3.0.2. IM, inner membrane; C, cytoplasm.

to previously described methods (Iwamoto et al., 2007) with slight modifications. In brief, cells in $500 \mu \mathrm{L}$ of M79 medium with $0.5 \%$ CA containing a glass strip along the wall of a 24-well plate (AGC, Tokyo, Japan) were fixed with 2\% glutaraldehyde (Wako Pure Chemical Industries, Osaka, Japan), stained with $\mathrm{OsO}_{4}$ (Nisshin EM Co., Ltd., Tokyo, Japan), subjected to solvent exchange, and lyophilized overnight. The cells on the glass strip were then coated with platinum (approximately $2 \mathrm{~nm}$ ) using an auto-fine coater (JEC-3000, JEOL, Tokyo, Japan), and observed with a fieldemission SEM, JSM-7800F Prime (JEOL), at an acceleration voltage of $5 \mathrm{kV}$, according to previously described methods (Iwamoto et al., 2007).

\section{Biofilm Observation by Confocal Laser Scanning Microscopy}

Biofilms of HM13-Rif ${ }^{\mathrm{r}}$ and the mutant were observed by confocal laser scanning microscopy (CLSM), according to previously described methods (Sabaeifard et al., 2017) with slight modifications. In brief, biofilms on a glass-base dish (AGC), obtained by static cultivation at $18^{\circ} \mathrm{C}$ for 3 days in $2 \mathrm{~mL}$ of M79 medium supplemented with $0.5 \%$ CA, were washed with DPBS twice, then stained with 1000-fold diluted propidium iodide and SYTO 9 (LIVE/DEAD ${ }^{\circledR}$ BacLight $^{\text {TM }}$ Bacterial Viability Kit, Molecular Probes/Thermo Fisher Scientific) at room temperature in darkness for $15 \mathrm{~min}$. The biofilms were observed at the air-liquid interface by CLSM using a $60 \times$ objective (FV3000, Olympus, Tokyo, Japan) with an excitation laser at $488 \mathrm{~nm}$.

\section{Quantification and Visualization of Biofilm With BiofilmQ}

The biofilm images from three frames obtained by CLSM were quantified, and representative images were modeled with the biofilm analysis software BiofilmQ ${ }^{4}$, and the image software ParaView ${ }^{5}$, according to previously described methods (Hartmann et al., 2019).

\section{Protein Identification by Proteome Analysis}

Cells of $S$. vesiculosa HM13, statically cultured in $5 \mathrm{~mL}$ of M79 media with 0.26 and $2.6 \mathrm{~g} / \mathrm{L}$ Lys at $18^{\circ} \mathrm{C}$ for 3 days, were homogenized by sonication in lysis buffer (7 M urea, 2 $\mathrm{M}$ thiourea, 2\% 3-[(3-cholamidopropyl)-dimethylammonio]-1propanesulfonate, $10 \mathrm{mM}$ dithiothreitol, and $50 \mathrm{mM}$ Tris- $\mathrm{HCl}$ $(\mathrm{pH} 7))$. The homogenate was centrifuged at $20,000 \times g$ at $4^{\circ} \mathrm{C}$ for $20 \mathrm{~min}$ to remove any remaining debris. The solvent was exchanged with $100 \mathrm{mM}$ triethylammonium bicarbonate (pH 8.5) with Amicon Ultra-0.5 (10-MWCO, Millipore, Billerica, MA, United States). Tris(2-carboxyethyl)phosphine $(0.2 \mathrm{M})$ was added to the sample, which was then incubated at $55^{\circ} \mathrm{C}$ for $60 \mathrm{~min}$. For alkylation, $375 \mathrm{mM} 2$-iodoacetamide was added, and the sample was incubated at room temperature in darkness for $30 \mathrm{~min}$. Then, cold acetone was added to the sample, which was then incubated at $-30^{\circ} \mathrm{C}$ for $3 \mathrm{~h}$. Next, the sample was centrifuged at $4^{\circ} \mathrm{C}$ and $20,300 \times g$ for $15 \mathrm{~min}$, dried at room temperature, and then suspended in $50 \mathrm{mM}$ triethylammonium bicarbonate. The proteins in the sample

\footnotetext{
${ }^{4}$ https://drescherlab.org/data/biofilmQ/docs/index.html

${ }^{5}$ https://www.paraview.org/
} 
were digested with $10 \mu \mathrm{g} / \mathrm{mL}$ sequence grade modified trypsin (Promega Corporation, Madison, WI, United States) at $37^{\circ} \mathrm{C}$ overnight. The digested proteins were labeled by incubation with TMT Mass Tagging Kits and Reagents (Thermo Fischer Scientific, Rockford, IL, United States) in dehydrated acetonitrile at room temperature for $1 \mathrm{~h}$. Then, 5\% hydroxylamine was added to the sample, which was then incubated at room temperature for $15 \mathrm{~min}$. Finally, the sample was frozen with liquid nitrogen and stored at $-80^{\circ} \mathrm{C}$ for proteome analysis.

The proteins in the sample were subjected to tandem mass taglabeling proteomic analysis, according to previously described methods (Tsuji et al., 2020). Proteins were identified by MASCOT search against the $S$. vesiculosa HM13 protein database. The fold-change values were determined as peptide abundance ratios between the cells grown with 0.26 and $2.6 \mathrm{~g} / \mathrm{L}$ Lys. The global median normalization method was used to normalize the amount of tryptic digests subjected to the analysis. Changes with $p$-values lower than 0.05 were considered statistically significant, and the corresponding genes were annotated by BLAST search and are listed in Table 4.

\section{RESULTS}

\section{Variation of Vesiculation Depending on Extracellular Environment}

To investigate whether S. vesiculosa HM13 regulates vesiculation in response to the extracellular environment, EMVs of this strain cultured in different media were characterized. We used the following three culture media: the rich nutrient LB, a minimal synthetic M79 medium (Papa et al., 2006), and MB, which is generally used for cultivating heterotrophic marine bacteria. The amount of EMVs at the early stationary phase $\left(\mathrm{OD}_{660} \approx\right.$ 2.5 in LB and 2.0 in M79 medium and MB) (Supplementary Figure 1A) was quantified by lipid staining (Figure 1), which showed that this strain cultured in the nutrient-poor conditions of M79 medium produced fewer EMVs than in the rich nutrient $\mathrm{LB}$, and the amount of EMVs in MB was much lower than that in the other media. Consistent with a previous study (Chen et al., 2020), this strain cultured in LB produced a single major protein, P49, in the EMV fraction, while other proteins were barely visible in both the EMV fraction and the PVF, the latter consisting of the supernatant obtained after ultracentrifugation to remove EMVs (Supplementary Figure 1B). Conversely, in M79 medium and MB, P49 was detected in both EMV fractions and PVFs (Supplementary Figure 1B).

\section{Identification of a Sensor Protein in EMVs}

To further characterize EMVs and obtain insights into the mechanism of their biogenesis, proteins in EMVs of the $g s p D 2$-disrupted mutant $(\triangle g s p D 2)$ were identified by gel-based proteomics. For this experiment, $\Delta g s p D 2$, which lacks a putative outer membrane conduit for transport of P49 to EMVs, was used as the disruption of $g s p D 2$ does not impair the production of EMVs (Chen et al., 2020; Kamasaka et al., 2020) and facilitates the identification of minor cargo proteins of EMVs owing to the absence of the major cargo protein P49. Indeed, in EMVs from the parental strain, the amount of P49 is much higher than that of other proteins, and this phenomenon prevents the identification of other proteins by 2D-PAGE owing to the limited protein-loading capacity of the gel.

EMVs from $\Delta g s p D 2$ were subjected to 2D-PAGE (Figure 2), and protein spots indicated by the black arrowheads in Figure 2 were identified by peptide mass fingerprinting (Table 3). It is noteworthy that most of them were predicted to be cytosolic and inner membrane proteins; in fact, proteins estimated to localize in the cytoplasm and inner membranes are often found in EMVs (Toyofuku et al., 2015; Jain and Pillai, 2017; Tan et al., 2018). This fact may be at least partially explained by the occurrence of outer-inner membrane vesicles (O-IMVs) secreted by various Gram-negative bacteria (Pérez-Cruz et al., 2013, 2015, 2016).

Among these proteins, that encoded by $h m 1275$ (spot \#7 in Figure 2) was profiled using BLAST (Altschul et al., 1997) and HHpred (Söding et al., 2005), which showed that this protein has structural features similar to those of a typical bacterial MCP, which carries a PAS domain to sense signals (Henry and Crosson, 2011) and an MCP signaling domain that interacts with other downstream proteins (Supplementary Table 1; Falke et al., 1997; Ud-Din and Roujeinikova, 2017). Although proteins that contain PAS and MCP domains generally play a role in signal transduction followed by chemotaxis (Henry and Crosson, 2011), some of these chemosensory components regulate nonchemotaxis-related functions (Wadhams and Armitage, 2004). For example, MCPs have been reported to be involved not only in motility, but also in other bacterial functions, including virulence and biofilm formation (Choi et al., 2015); thus, experimental data are needed to elucidate the function of HM1275. Since HM1275 was predicted to be a membrane protein using PSORTb (Yu et al., 2010), its properties may have caused its abnormal migration in 2D-PAGE, where its apparent molecular mass differed from the calculated mass reported in Table 3; in fact, this phenomenon also occurred for other membrane proteins (Rath et al., 2009; Rath and Deber, 2013).

\section{Induction of Vesicle Production Mediated by a Putative Sensor Protein, HM1275, in the Presence of a High Concentration of Lys}

We then examined whether HM1275 senses signal molecules in the extracellular environment and regulates vesicle production. To facilitate the identification of a signal molecule that affects vesicle production, a totally synthetic and nutrient-poor M79 medium was used for this experiment. Within its components, we focused on amino acids, previously reported as signal molecules for MCPs in bacteria (Springer et al., 1977; Hedblom and Adler, 1980; Hanlon and Ordal, 1994). In particular, we focused on the concentration of Lys, which is abundant in zooplankton (Kolmakova and Kolmakov, 2019). The latter is the most typical diet of horse mackerel (Jardas et al., 2004), from whose intestines S. vesiculosa HM13 was isolated (Chen et al., 2020). Therefore, we hypothesized that Lys concentration may be sensed by this 
TABLE 4 | Change of protein expression in response to Lys concentration.

\begin{tabular}{|c|c|c|c|c|}
\hline Gene & Fold change ${ }^{a}$ & Protein $^{\mathbf{b}}$ & $p$-value ${ }^{c}$ & Accession \\
\hline hm3452 & 1.59 & SSU ribosomal protein S16p & $1.8 \times 10^{-2}$ & LC533463 \\
\hline$h m 2439$ & 1.38 & Cytochrome $c$ oxidase subunit $\mathrm{CcoO}$ & $4.6 \times 10^{-2}$ & LC547421 \\
\hline$h m 1357$ & 0.56 & Cell division protein BolA & $7.7 \times 10^{-3}$ & LC547422 \\
\hline hm4008 & 0.54 & Hypothetical protein & $7.7 \times 10^{-3}$ & LC547423 \\
\hline hm498 & 0.52 & Isoquinoline 1-oxidoreductase alpha subunit & $3.4 \times 10^{-2}$ & LC547424 \\
\hline hm4042 & 0.51 & TRAP transporter solute receptor, unknown substrate 1 & $3.8 \times 10^{-2}$ & LC547425 \\
\hline hm3656 & 0.50 & Hypothetical protein & $2.0 \times 10^{-2}$ & LC547426 \\
\hline hm4030 & 0.50 & Methionine repressor MetJ & $4.8 \times 10^{-2}$ & LC533496 \\
\hline$h m 244$ & 0.46 & Secreted and surface protein containing fasciclin-like repeats & $9.5 \times 10^{-3}$ & LC533506 \\
\hline hm1567 & 0.45 & Hypothetical protein & $3.8 \times 10^{-2}$ & LC533509 \\
\hline hm810 & 0.22 & Hypothetical protein & $3.6 \times 10^{-4}$ & LC533516 \\
\hline$h m 2742$ & 0.20 & Cold shock protein CspD & $1.2 \times 10^{-2}$ & LC533517 \\
\hline hm4032 & 0.18 & Cytochrome $c$ family protein & $4.1 \times 10^{-2}$ & LC533518 \\
\hline
\end{tabular}

${ }^{a}$ Fold changes were calculated by dividing the average expression values relative to $2.6 \mathrm{~g} / \mathrm{L}$ Lys-grown cells by those of $0.26 \mathrm{~g} / \mathrm{L}$ Lys-grown cells.

${ }^{b}$ Proteins in the database showing the highest sequence similarity to the proteins from S. vesiculosa HM13.

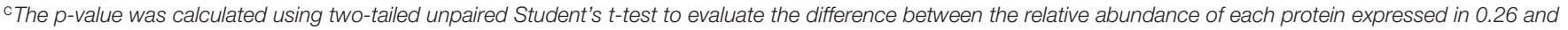
$2.6 \mathrm{~g} / \mathrm{L}$ Lys-grown cells.

strain as a marker of environmental change caused by food intake by the host; thus, we cultivated bacterial cells in media containing Lys at physiological concentrations (up to $2.6 \mathrm{~g} / \mathrm{L}$ ) for subsequent experiments (for details, please refer to the "Materials and Methods" section).

An $h m 1275$-disrupted strain $(\Delta h m 1275)$ was prepared as described in the "Materials and Methods" section. The growth of this strain was similar to that of its parental strain (HM13Rif $^{\mathrm{r}}$ ) in M79 + CA (Supplementary Figure 2). Next, these two strains were cultured in modified M79 media supplemented with different concentrations of Lys. The relative vesicle production of HM13-Rif ${ }^{\mathrm{r}}$, quantified by lipid staining, increased in a Lys concentration-dependent manner (Figure 3). Similar tendencies were observed by nanoparticle tracking analysis (Supplementary Figure 3A; Filipe et al., 2010). Lys concentration-dependent increase in the growth was also observed, but it was less significant than that in the vesicle production (Supplementary Figure 4). EMVs produced under these conditions had similar mean diameters, although smaller EMVs were more abundant in the presence of $1.3 \mathrm{~g} / \mathrm{L}$ Lys than in other conditions (Supplementary Figure 3B). Notably, HM13-Rif ${ }^{\mathrm{r}}$ cultured in M79 medium with $2.6 \mathrm{~g} / \mathrm{L}$ Lys produced an approximately fourfold larger number of EMVs compared to the same strain grown in original M79 medium containing $0.26 \mathrm{~g} / \mathrm{L}$ Lys. However, Lys-induced vesicle production by $\Delta h m 1275$ was significantly lower than that of HM13-Rif ${ }^{\mathrm{r}}$ (Figure 3). Nevertheless, under all conditions, transmission electron microscopy did not reveal any morphological differences between EMVs from these strains (Supplementary Figure 5). Effects of the hm1275 disruption on the Lys-dependent growth increase were also less significant than those on the Lys-induced vesicle production (Supplementary Figure 4).

To confirm that the suppression of the Lys-induced vesicle production (Figure 3) was caused by the disruption of $h m 1275$, the complemented strain of $\Delta h m 1275(\Delta h m 1275 / \mathrm{phm} 1275)$ and an empty vector-introduced strain $(\Delta h m 1275 / \mathrm{p})$ were used. In
M79 media with $2.6 \mathrm{~g} / \mathrm{L}$ Lys, the relative vesicle production of $\Delta h m 1275 / \mathrm{phm} 1275$ was significantly higher than that of $\Delta h m 1275 / p$ (Supplementary Figure 6), suggesting that the disruption of $h m 1275$ caused the observed phenotype.

\section{Repression of HM1275-Dependent Biofilm Formation}

To adapt to the extracellular environment, bacteria accurately control the transition between planktonic and biofilm states (Rossi et al., 2018). Interestingly, pairwise alignment of amino

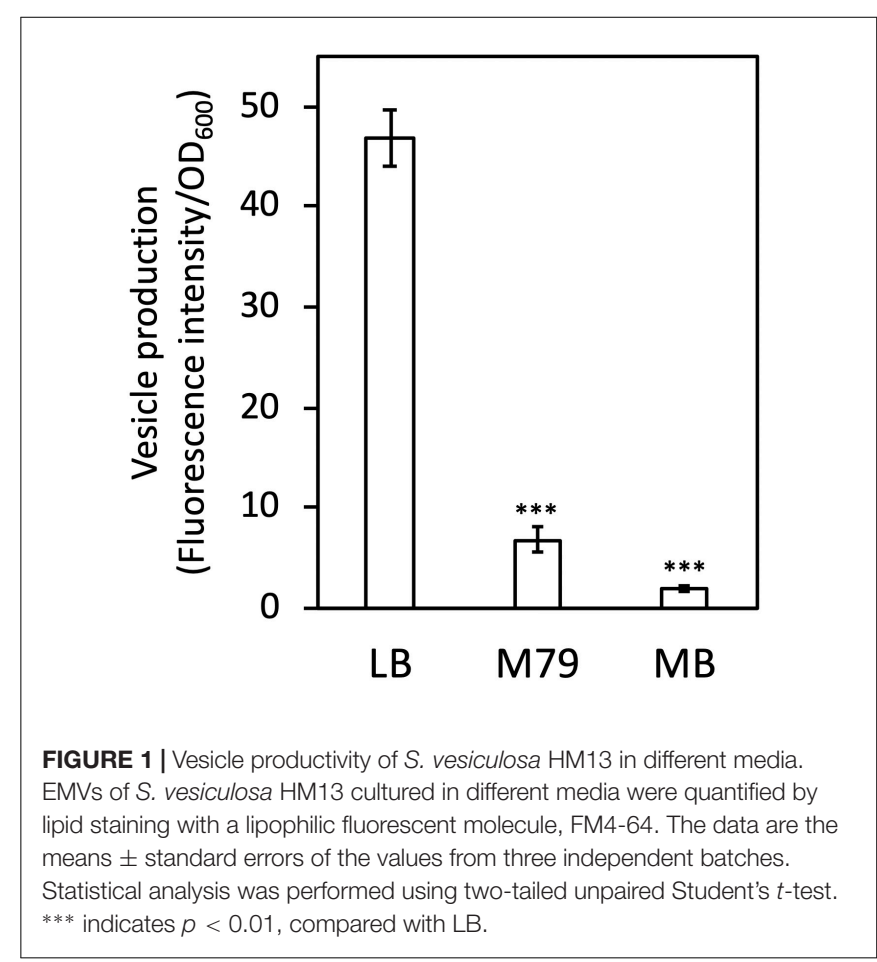




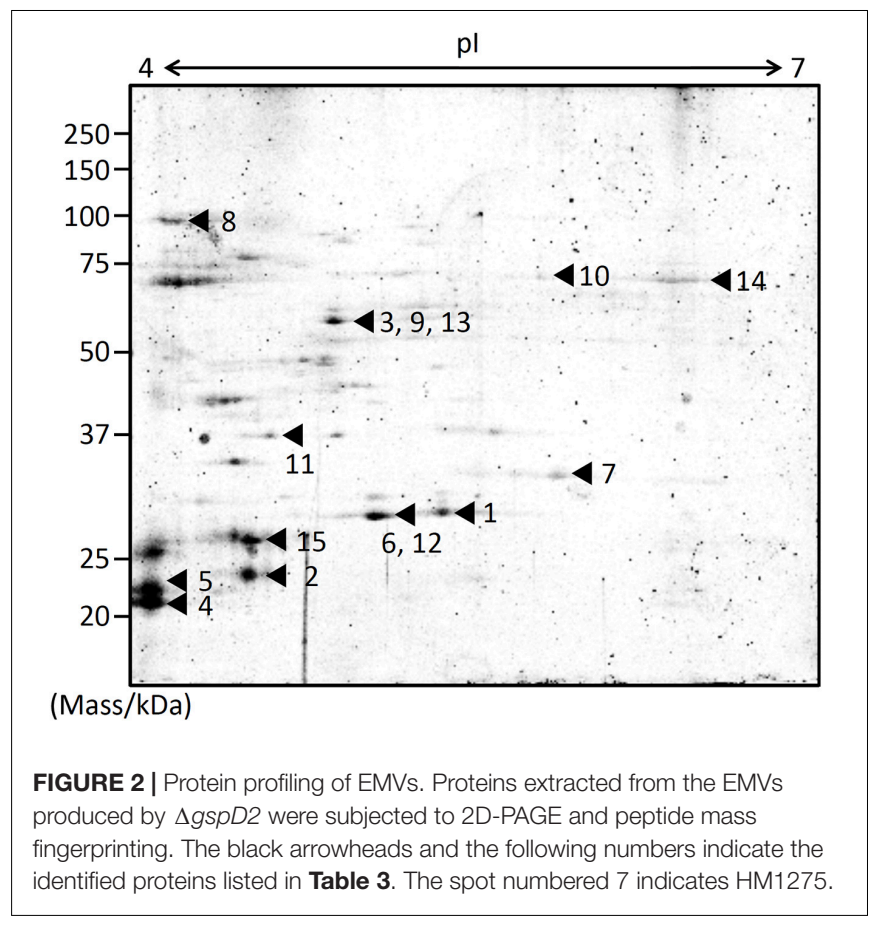

acid sequences with Clustal Omega ${ }^{6}$ (Sievers et al., 2011) revealed that HM1275 has a $38.8 \%$ sequence identity to BdlA,

${ }^{6}$ https://www.ebi.ac.uk/Tools/msa/clustalo/ a protein related to biofilm dispersion in $P$. aeruginosa $\mathrm{PAO} 1$ (accession number: Q9I3S1; Supplementary Figure 7; Morgan et al., 2006; Barraud et al., 2009; Petrova and Sauer, 2012). This protein plays a role in sensing the extracellular environment and downregulates the accumulation of cyclic-di-GMP to induce biofilm dispersion. This sequence similarity suggests that HM1275 is not only involved in vesicle production, but also in biofilm formation (Bobrov et al., 2005; Thormann et al., 2006). Therefore, biofilm formation by HM13-Rif ${ }^{\mathrm{r}}$ and $\Delta h m 1275$ was measured over time by staining with CV (Thormann et al., 2004). We observed that the amount of biofilm in HM13-Rif ${ }^{\mathrm{r}}$ decreased in a time-dependent manner, but such a decrease was much less significant in the mutant (Figure 4A).

To examine whether biofilm formation is controlled by Lys concentration in an HM1275-dependent manner, similar to vesicle production, biofilm formation of HM13-Rif ${ }^{\mathrm{r}}$ and $\Delta h m 1275$ cultured in M79 media supplemented with CA and Lys was quantified (Figure 4B). Under all conditions tested, the relative amounts of biofilm from HM13-Rif ${ }^{\mathrm{r}}$ were lower than those of $\Delta h m 1275$ ( $p=0.067,0.073$, and 0.025 for bacteria grown in M79, M79 + CA, and M79 + Lys, respectively) and the empty vector-introduced strain $(\Delta h m 1275 / p)(p=0.010,0.0062$, and 0.0024 for bacteria grown in M79, M79 + CA, and M79 + Lys, respectively), but were not significantly different from those of the complemented strain $(\Delta h m 1275 / \mathrm{phm1275})$. Moreover, the amounts of biofilm from HM13-Rif ${ }^{\mathrm{r}}$ decreased to $16.8 \%$ upon addition of CA and to $12.0 \%$ upon addition of Lys, whereas those of the mutant decreased by a lesser extent upon addition of CA (65.1\%) and Lys (68.3\%), compared with those in the original

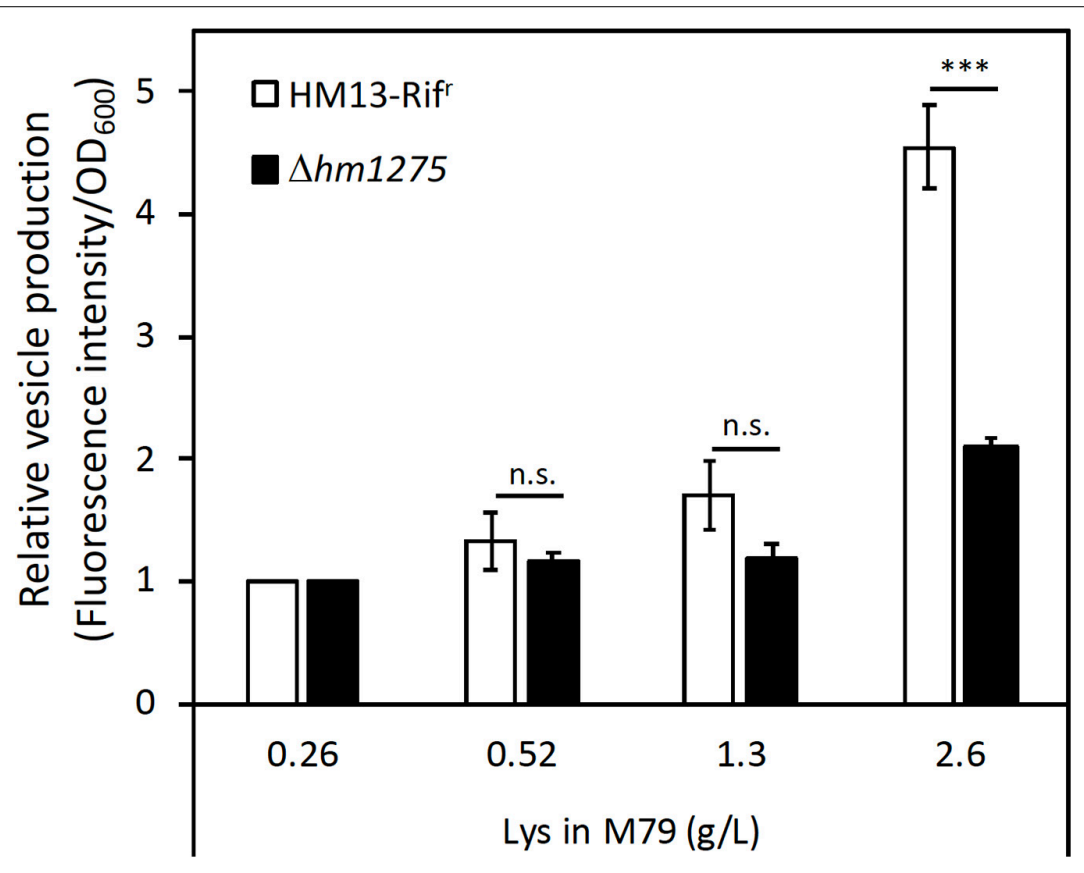

FIGURE 3 | Induced vesicle production of S. vesiculosa HM13 by the addition of Lys in a concentration-dependent manner. The vesicle production of HM13-Rifr and $\Delta h m 1275$ cultured at different Lys concentrations was quantified by lipid staining. Each value of vesicle production was divided by that of cells grown in M79 containing $0.26 \mathrm{~g} / \mathrm{L}$ Lys to compare relative vesicle production in each condition. The data are the means \pm relative standard errors of the values from three independent batches. Statistical analysis was performed using two-tailed unpaired Student's $t$-test. n.s. and *** indicate $p \geq 0.1$ and $p<0.01$, respectively. 


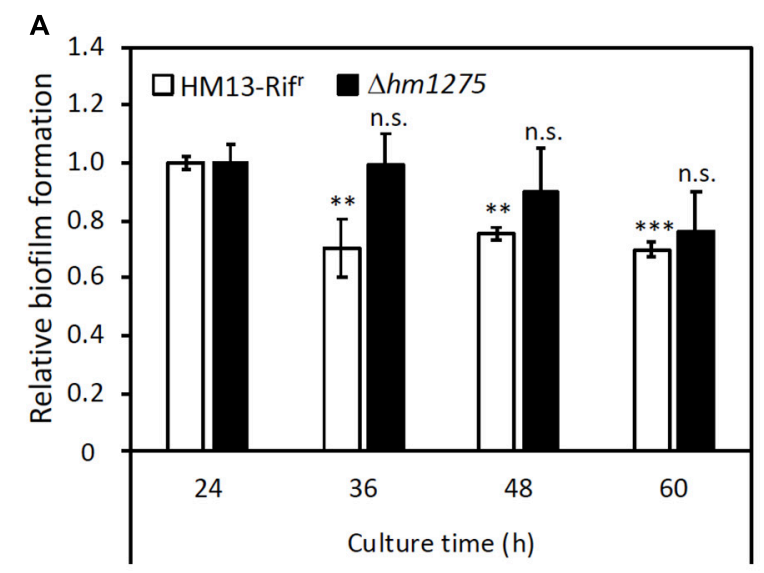

B

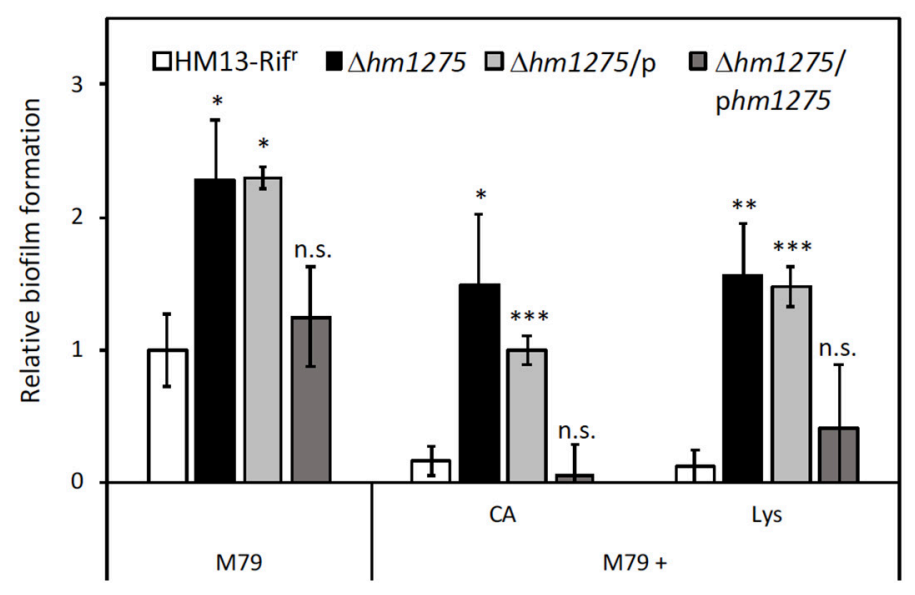

C

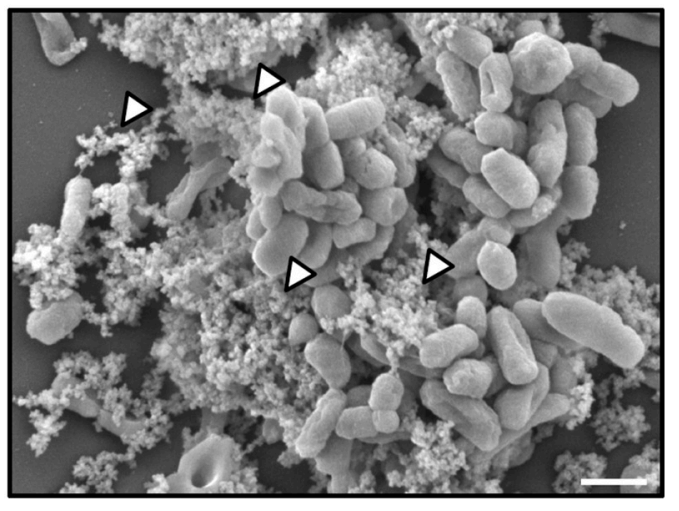

。

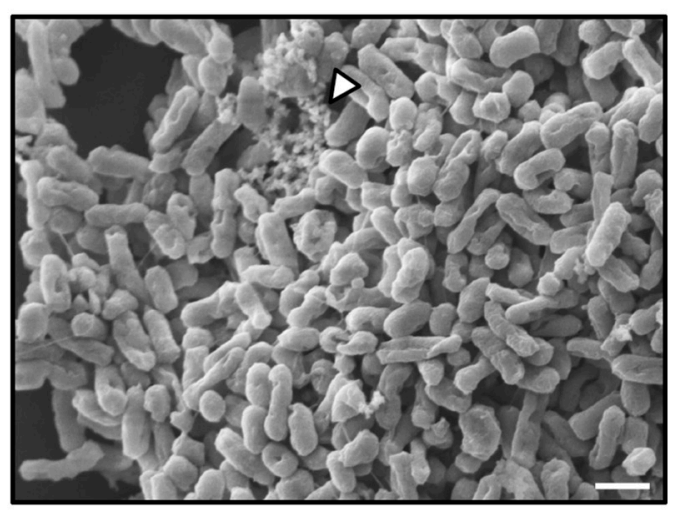

FIGURE 4 | Suppression of biofilm formation of S. vesiculosa HM13 by the addition of Lys. (A) The biofilm formation of HM13-Rif' and $\Delta$ hm1275 cultured in M79 + CA was quantified in time-course by staining with CV. (B) Biofilm formation of HM13-Rifr and $\Delta$ hm1275 in modified M79 media was quantified after $72 \mathrm{~h}$ of cultivation by staining with CV. The data are the means \pm relative standard errors of the values from three independent batches. Statistical analyses for differences between $24 \mathrm{~h}$ and other culture times (A) and for differences between HM13-Rifr and other strains in each cultivation condition (B) were performed using two-tailed unpaired Student's t-test. n.s., *, **, and *** indicate $p \geq 0.1$, and $p<0.1,0.05$, and 0.01, respectively. (C,D) The fine structures of biofilm of HM13-Rifr (C) and $\Delta h m 1275$ (D) cultured in M79 + CA were observed by SEM. The white arrowheads indicate stackings of EMV-like structures. The bars indicate $1 \mu \mathrm{m}$.

M79 medium. These results suggest that HM1275 is involved in Lys-induced suppression of biofilm formation.

Next, we analyzed the fine structures of biofilms of HM13Rif $^{\mathrm{r}}$ and $\Delta h m 1275$ by SEM. Some stackings of EMV-like structures were frequently observed in HM13-Rif ${ }^{\mathrm{T}}$ biofilm (white arrowheads in Figure 4C). Conversely, such structures were much less frequently observed in the mutant biofilm (white arrowheads in Figure 4D).

\section{Increased Population of Dead Cells in the Biofilm of $\Delta h m 1275$}

We further investigated the biomass and live/dead cell ratio in biofilms of HM13-Rif ${ }^{r}$ and $\Delta h m 1275$ by CLSM. For HM13Rif ${ }^{\mathrm{r}}$, a small amount of biofilm (red square in Figure 5A) and many single cells attached to the glass bottom of the dish base were observed (Figure 5A) compared with the mutant, for which a large amount of biofilm was observed (Figure 5B). Furthermore, mutant biofilms contained a larger number of dead cells than HM13-Rif ${ }^{\mathrm{r}}$ biofilms (Figures 5A,B). In particular, the sectioned images in CLSM and models of biofilm indicated that the HM13-Rif ${ }^{\mathrm{r}}$ biofilm included a small number of dead cells in its interior region (Figures $\mathbf{5} \mathbf{A}, \mathbf{C}$ ), whereas the $\Delta h m 1275$ biofilm included abundant dead cells at the bottom and in its interior region (Figures 5B,D). Biomass quantification of the biofilm of these strains showed that the total biomass of the mutant biofilm was approximately five-fold larger than that of the HM13Rif $^{\mathrm{r}}$ biofilm (Figure 5E). However, the HM13-Rif ${ }^{\mathrm{r}}$ biofilm was composed of approximately $80 \%$ live and $20 \%$ dead cells, while the mutant biofilm was composed of approximately $53 \%$ live and $47 \%$ dead cells.

\section{Comprehensive Identification of Lys-Induced and -Repressed Proteins}

To obtain insights into the mechanisms of Lys-induced vesicle production and suppression of biofilm formation mediated by HM1275, proteins up- and downregulated by increasing 


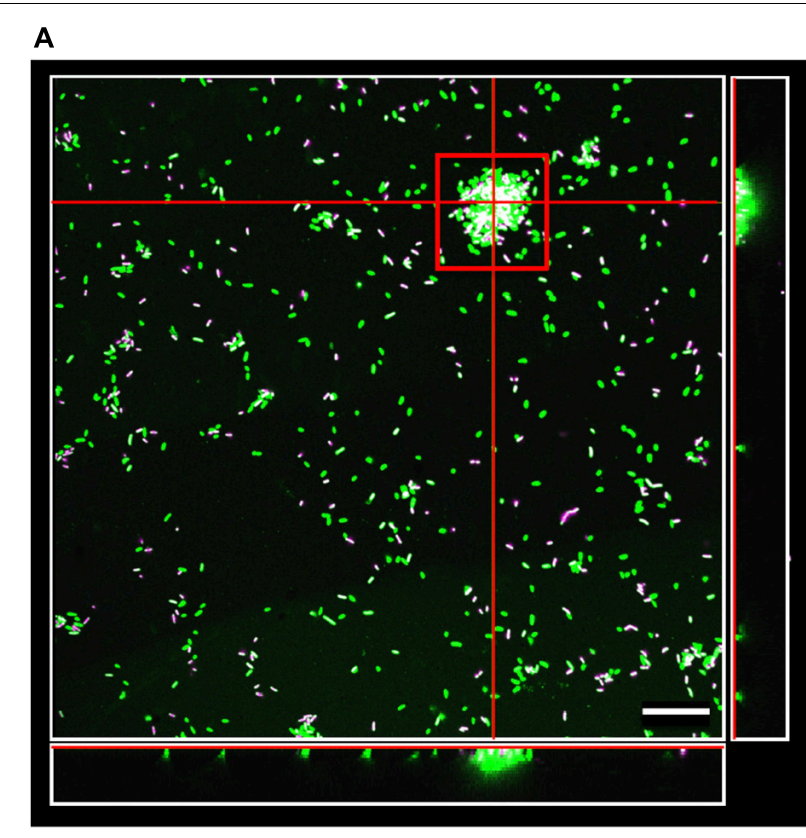

C

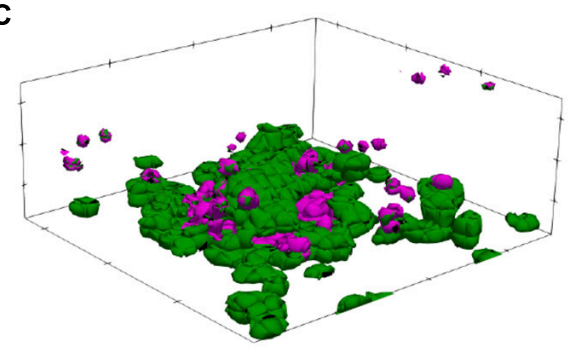

D
B
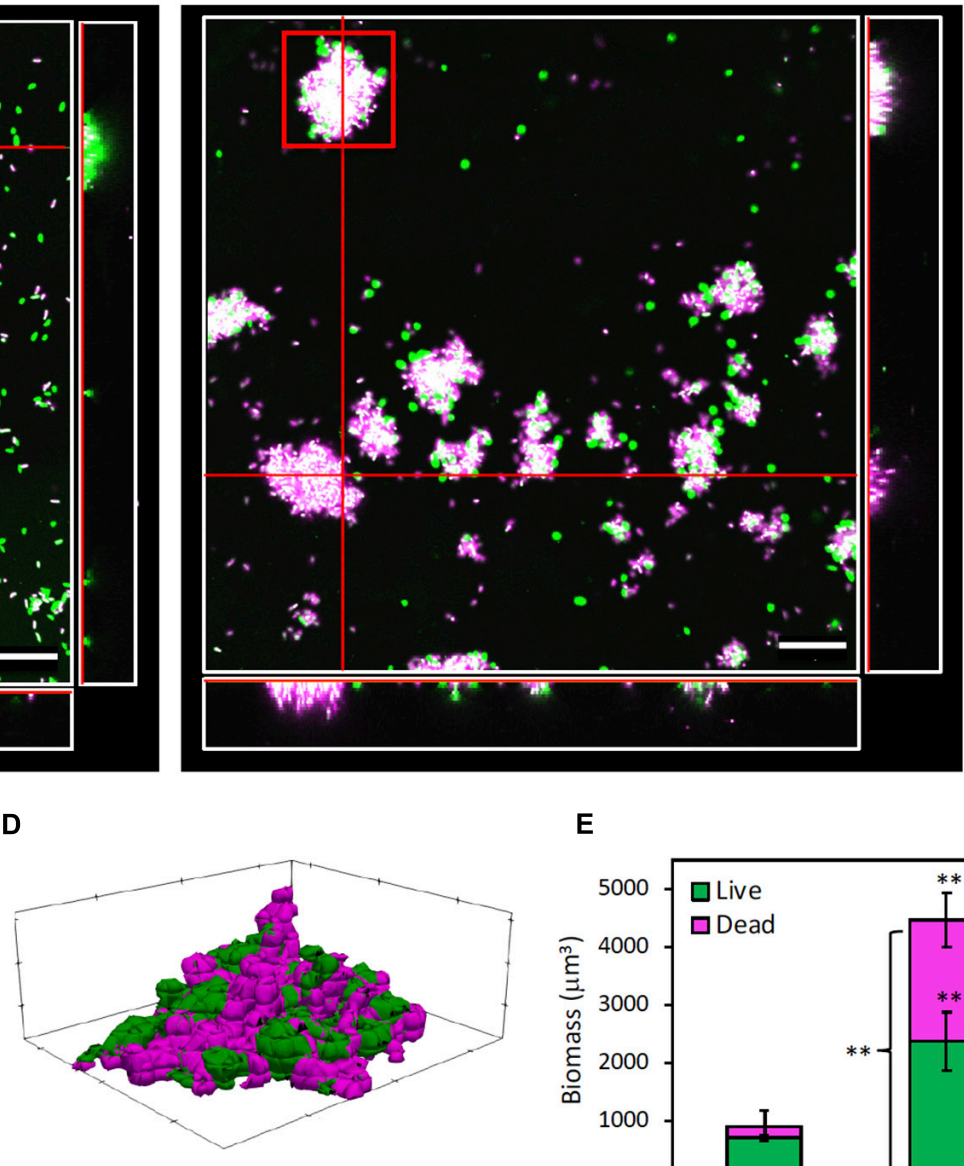

E

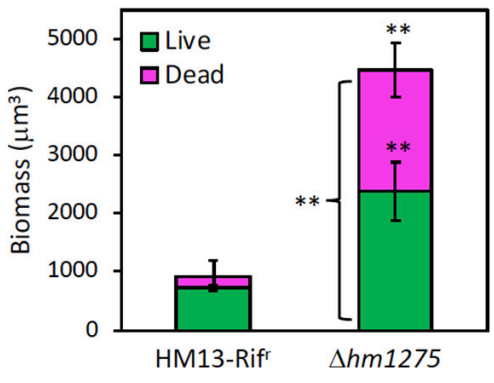

FIGURE 5 | Live/dead cell analysis of surface-associated cells of HM13-Rifr and $\Delta h m 1275$. Surface-associated cells of HM13-Rifr ${ }^{\text {(A) }}$ and $\Delta h m 1275$ (B) cultured in M79 + CA were observed by CLSM. Green, magenta, and white colors indicate living and dead cells, and merged colors, respectively. The white boxes at the right and bottom of each image show cross-sections at the vertical and horizontal red lines in the center white box, respectively. The central white box of each image shows a side-cross-section at the red lines in the right and bottom white boxes. The bars indicate $20 \mu \mathrm{m}$. (C,D) Models of biofilm of HM13-Rifr (C) and $\Delta h m 1275$ (D) in the red square in (A,B) were constructed with BiofilmQ and ParaView. (E) The biomass and live/dead ratio in biofilm were quantified with BiofilmQ. The data are the means \pm standard errors of the values from three independent batches. Statistical analysis was performed for differences between $\mathrm{HM} 13-\mathrm{Rifr}$ and $\Delta h m 1275$ using two-tailed unpaired Student's t-test. ${ }^{* *}$ indicates $p<0.05$.

the concentration of Lys in the medium from 0.26 to $2.6 \mathrm{~g} / \mathrm{L}$ were identified by shotgun proteomics (Supplementary Figure 8). Proteome analysis covered approximately $35 \%$ of all gene products of $S$. vesiculosa HM13. The genes encoding proteins that showed significant differences in expression levels between cells grown with 0.26 and $2.6 \mathrm{~g} / \mathrm{L}$ Lys were annotated by a BLAST search and are listed in Table 4. These proteins $(n=13)$ accounted for approximately $1 \%$ of the total proteome $(n=1,488)$. Among these proteins, two proteins, a ribosome subunit and a cytochrome $c$ oxidase subunit (HM3452 and HM2439, respectively), were slightly upregulated (Table 4). On the other hand, 11 downregulated proteins included proteins related to cell division (HM1357), redox reaction (HM498 and HM4032), transcriptional regulation (HM4030), transportation (HM4042), cell adhesion (HM244), and DNA replication (HM2742)
(Table 4). The possible involvement of these proteins in vesicle production and biofilm formation will be discussed in the "Discussion" section.

\section{DISCUSSION}

In this study, we found that the putative sensor protein HM1275 of S. vesiculosa HM13 is involved in the regulation of vesicle production and biofilm formation. Vesicle production and suppression of biofilm formation were co-induced through HM1275 in response to high Lys concentrations, suggesting a common regulation mechanism shared between these physiological responses.

To explore the mechanism of HM1275-mediated response to extracellular Lys concentration, we identified proteins whose 
expression levels were significantly changed in response to Lys concentration. When the cells were grown with high concentrations of Lys, HM1357, a homolog of a cell division-related protein, BolA, was downregulated (0.56fold) compared with its expression in cells grown with low concentrations of Lys (Table 4). BolA regulates the transcript levels of several proteins involved in peptidoglycan synthesis, and its deletion causes loss of integrity of the outer membrane (Freire et al., 2006). Furthermore, the deletion of a gene coding for a BolA-like protein, IbaG, reduces peptidoglycan levels and alters outer membrane lipids, disturbing membrane integrity (Fleurie et al., 2019). Decreased membrane peptidoglycan cross-linking plays a role in vesicle formation in Gram-negative bacteria (Nagakubo et al., 2020). Therefore, it is plausible that the downregulated expression of HM1357, a BolA-like protein of S. vesiculosa HM13, reduces the stability of the peptidoglycan network and weakens the linkage between peptidoglycan layers and the outer membrane, thereby inducing membrane blebbing and subsequent vesicle production.

We found that HM1275 is also involved in Lys-induced suppression of biofilm formation. Therefore, cells are also supposed to regulate the expression of proteins related to biofilm formation in response to Lys. BolA is also involved in biofilm formation by facilitating the production of fimbrialike adhesins and curli, and negatively modulating flagellar biosynthesis and swimming capacity (Dressaire et al., 2015). Even in the presence of an abundant biofilm-forming factor, cyclic-di-GMP, the absence of BolA reduced the amount of biofilm (Moreira et al., 2017). Therefore, we speculate that HM1275 senses extracellular signals and downregulates the expression of the BolA-like protein HM1357 to suppress biofilm formation.

We also found that HM244, a homolog of a secreted and surface protein containing fasciclin-like repeats, was 0.46 -fold downregulated under high Lys conditions (Table 4). The fasciclin domain is involved in cell attachment across plants, animals, and bacteria (Seifert, 2018). Therefore, the decreased production of HM244 in response to high Lys concentration may decrease biofilm formation by suppressing cell adhesion.

Biofilm formation may play an important role in the survival of $S$. vesiculosa HM13 in its original habitat. This strain was isolated from fish intestines, where nutrients fluctuate depending on the feeding activity of the fish; thus, this bacterium should cope well with nutrient fluctuations for its survival (Pereira and Berry, 2017). When nutrients are scarce in the host intestine, biofilm formation is thought to be beneficial for bacterial survival, as reported for various strains (Falkinham, 2009; Cherifi et al., 2017). On the other hand, when the host fish ingests food, the digested food is introduced to the intestine, rendering the environment suitable for bacteria to proliferate. Under these conditions, it is likely that S. vesiculosa HM13 cells respond to Lys, which is supposed to be abundant in the diet of the host fish, through the sensor protein HM1275, thereby suppressing biofilm formation. Inside and at the bottom of the biofilm, cells are subjected to low oxygen and nutrient availability (Flemming et al., 2016). Consequently, if the cells cannot properly suppress biofilm formation under nutrient-rich conditions, they cannot benefit from such conditions and are expected to die because of the limited resources available in the biofilm (Figure 5; Cherifi et al., 2017). Therefore, regulation of biofilm formation in a timely manner, probably by HM1275, contributes to the survival of this strain in a changeable environment.

HM1275 was identified as a cargo of EMVs (Figure 2), although it was predicted to localize to the inner membrane by PSORTb (Yu et al., 2010; Table 3). These results suggest that HM1275 found in the EMV fraction is included in O-IMVs, which display membranes derived from the cell's inner membrane and are produced by various Gram-negative bacteria as a minor fraction of EMVs (Pérez-Cruz et al., 2013, 2015, 2016). This interpretation is supported by our previous observation that S. vesiculosa HM13 produces EMVs with a double membranebounded structure, which are supposed to be O-IMVs (Chen et al., 2020). On the other hand, the physiological significance of the occurrence of HM1275 in EMVs is currently unknown. As a putative sensor protein, HM1275 is thought to play a role in the cellular inner membrane, where it performs signaling functions that facilitate EMV production and suppression of biofilm formation. Thus, HM1275 packaged into EMVs may not have an active role, but rather be eliminated from the cells as a result of protein quality control (McBroom and Kuehn, 2006) or released into the culture supernatant as a result of explosive cell lysis (Turnbull et al., 2016). Nevertheless, another hypothesis may also be that EMVs function as a carrier of HM1275 for the transfer of this protein to other cells to facilitate collective cell behavior such as the regulation of biofilm formation, although, to our knowledge, the intercellular transfer of inner membrane proteins has not been demonstrated so far. These hypotheses should be examined in future studies. Although the physiological significance of HM1275 in EMVs remains elusive, the present study revealed that a putative sensor protein is involved in nutrient-responsive co-regulation of EMV production and biofilm formation. A possible functional link between EMV production and biofilm formation will also be examined in future studies.

\section{DATA AVAILABILITY STATEMENT}

The datasets presented in this study can be found in online repositories. The names of the repository/repositories and accession number(s) can be found below: https: //www.ddbj.nig.ac.jp/, LC533412 https://www.ddbj.nig.ac.jp/, LC533413 https://www.ddbj.nig.ac.jp/, LC533414 https: //www.ddbj.nig.ac.jp/, LC533415 https://www.ddbj.nig.ac.jp/, LC533416 https://www.ddbj.nig.ac.jp/, LC533417 https: //www.ddbj.nig.ac.jp/, LC533418 https://www.ddbj.nig.ac.jp/, LC533419 https://www.ddbj.nig.ac.jp/, LC533420 https: //www.ddbj.nig.ac.jp/, LC533421 https://www.ddbj.nig.ac.jp/, LC533422 https://www.ddbj.nig.ac.jp/, LC533423 https: //www.ddbj.nig.ac.jp/, LC533424 https://www.ddbj.nig.ac.jp/, LC533425 https://www.ddbj.nig.ac.jp/, LC533426 https: //www.ddbj.nig.ac.jp/, LC533463 https://www.ddbj.nig.ac.jp/, LC547421 https://www.ddbj.nig.ac.jp/, LC547422 
https://www.ddbj.nig.ac.jp/, LC547423 https://www.ddbj.nig. ac.jp/, LC547424 https://www.ddbj.nig.ac.jp/, LC547425 https: //www.ddbj.nig.ac.jp/, LC547426 https://www.ddbj.nig.ac.jp/, LC533496 https://www.ddbj.nig.ac.jp/, LC533506 https://www. ddbj.nig.ac.jp/, LC533509 https://www.ddbj.nig.ac.jp/, LC533516 https://www.ddbj.nig.ac.jp/, LC533517 https://www.ddbj.nig.ac. jp/, LC533518.

\section{AUTHOR CONTRIBUTIONS}

FY, JK, and TK designed the study, discussed the results, and wrote the manuscript. FY performed the experiments. TI contributed to electron microscopic analysis. WA and MU contributed to proteome analysis. All authors have read and approved the submitted version.

\section{FUNDING}

This work was supported by research grants from the JSPS KAKENHI (JP15H04474, JP17H04598, JP18H02127, JP18K19178, and JP20K20570 to TK and JP16K14885 to JK),

\section{REFERENCES}

Alexeyev, M. F. (1999). The pKNOCK series of broad-host-range mobilizable suicide vectors for gene knockout and targeted DNA insertion into the chromosome of Gram-negative bacteria. BioTechniques 26, 824-828. doi: 10. 2144/99265bm05

Altschul, S. F., Madden, T. L., Schäffer, A. A., Zhang, J., Zhang, Z., Miller, W., et al. (1997). Gapped BLAST and PSI-BLAST: a new generation of protein database search programs. Nucleic Acids Res. 25, 3389-3402. doi: 10.1093/nar/25.17. 3389

Barraud, N., Schleheck, D., Klebensberger, J., Webb, J. S., Hassett, D. J., Rice, S. A., et al. (2009). Nitric oxide signaling in Pseudomonas aeruginosa biofilms mediates phosphodiesterase activity, decreased cyclic di-GMP levels, and enhanced dispersal. J. Bacteriol. 191, 7333-7342. doi: 10.1128/jb.009 75-09

Bitto, N., and Kaparakis-Liaskos, M. (2017). The therapeutic benefit of bacterial membrane vesicles. Int. J. Mol. Sci. 18:1287. doi: 10.3390/ijms18061287

Bobrov, A. G., Kirillina, O., and Perry, R. D. (2005). The phosphodiesterase activity of the HmsP EAL domain is required for negative regulation of biofilm formation in Yersinia pestis. FEMS Microbiol. Lett. 247, 123-130. doi: 10.1016/ j.femsle.2005.04.036

Chen, C., Kawamoto, J., Kawai, S., Tame, A., Kato, C., Imai, T., et al. (2020). Isolation of a novel bacterial strain capable of producing abundant extracellular membrane vesicles carrying a single major cargo protein and analysis of its transport mechanism. Front. Microbiol. 10:3001. doi: 10.3389/fmicb.2019.03001

Chen, Y.-C., Tou, J. C., and Jaczynski, J. (2009). Amino acid and mineral composition of protein and other components and their recovery yields from whole antarctic krill (Euphausia superba) using isoelectric solubilization/precipitation. J. Food Sci. 74, H31-H39. doi: 10.1111/j.1750-3841.2008.01026.x

Cherifi, T., Jacques, M., Quessy, S., and Fravalo, P. (2017). Impact of nutrient restriction on the structure of Listeria monocytogenes biofilm grown in a microfluidic system. Front. Microbiol. 8:864. doi: 10.3389/fmicb.2017.00864

Choi, Y., Kim, S., Hwang, H., Kim, K.-P., Kang, D.-H., and Ryu, S. (2015). Plasmidencoded MCP is involved in virulence, motility, and biofilm formation of Cronobacter sakazakii ATCC 29544. Infect. Immun. 83, 197-204. doi: 10.1128/ iai.02633-14 the Institute for Fermentation, Osaka (L-2019-2-012 to TK), and JSPS Research Fellowship for Young Scientists (to FY).

\section{ACKNOWLEDGMENTS}

We thank Prof. Hiroyuki Yano (Research Institute for Sustainable Humanosphere, Kyoto University) for SEM observation of bacterial biofilm; Prof. Shiroh Futaki and Dr. Kenichi Kawano (Institute for Chemical Research, Kyoto University) for CLSM analysis of bacterial biofilm; Prof. Kazunari Akiyoshi and Dr. Asako Shimoda (Graduate School of Engineering, Kyoto University) for nanoparticle tracking analysis of bacterial vesicles. Transmission electron microscopy was performed in collaboration with the Analysis and Development System for Advanced Materials (ADAM) at the Research Institute for Sustainable Humanosphere, Kyoto University.

\section{SUPPLEMENTARY MATERIAL}

The Supplementary Material for this article can be found online at: https://www.frontiersin.org/articles/10.3389/fmicb. 2021.629023/full\#supplementary-material

Dressaire, C., Moreira, R. N., Barahona, S., Matos, A. P. A., and Arraiano, C. M. (2015). BolA is a transcriptional switch that turns off motility and turns on biofilm development. mBio 6, 2352-2314e. doi: 10.1128/mbio.02352-14

Falke, J. J., Bass, R. B., Butler, S. L., Chervitz, S. A., and Danielson, M. A. (1997). The two-component signaling pathway of bacterial chemotaxis: a molecular view of signal transduction by receptors, kinases, and adaptation enzymes. Annu. Rev. Cell Dev. Biol. 13, 457-512. doi: 10.1146/annurev.cellbio.13.1.457

Falkinham, J. O. III (2009). Surrounded by mycobacteria: nontuberculous mycobacteria in the human environment. J. Appl. Microbiol. 107, 356-367. doi: 10.1111/j.1365-2672.2009.04161.x

Filipe, V., Hawe, A., and Jiskoot, W. (2010). Critical evaluation of nanoparticle tracking analysis (NTA) by NanoSight for the measurement of nanoparticles and protein aggregates. Pharmaceut. Res. 27, 796-810. doi: 10.1007/s11095010-0073-2

Flemming, H.-C., Wingender, J., Szewzyk, U., Steinberg, P., Rice, S. A., and Kjelleberg, S. (2016). Biofilms: an emergent form of bacterial life. Nat. Rev. Microbiol. 14:563. doi: 10.1038/nrmicro.2016.94

Fleurie, A., Zoued, A., Alvarez, L., Hines, K. M., Cava, F., Xu, L., et al. (2019). A Vibrio cholerae BolA-like protein is required for proper cell shape and cell envelope integrity. mBio 10, 790-719e. doi: 10.1128/mbio.00790-19

Freire, P., Vieira, H. L. A., Furtado, A. R., Pedro, M. A., and Arraiano, C. M. (2006). Effect of the morphogene bolA on the permeability of the Escherichia coli outer membrane. FEMS Microbiol. Lett. 260, 106-111. doi: 10.1111/j.1574-6968.2006. 00307.x

Guida, R. D., Casillo, A., Yokoyama, F., Kawamoto, J., Kurihara, T., and Corsaro, M. M. (2020). Detailed structural characterization of the lipooligosaccharide from the extracellular membrane vesicles of Shewanella vesiculosa HM13. Mar. Drugs 18:231. doi: 10.3390/md18050231

Hanlon, D. W., and Ordal, G. W. (1994). Cloning and characterization of genes encoding methyl-accepting chemotaxis proteins in Bacillus subtilis. J. Biol. Chem. 269, 14038-14046.

Hartmann, R., Jeckel, H., Jelli, E., Singh, P. K., Vaidya, S., Bayer, M., et al. (2019). BiofilmQ, a software tool for quantitative image analysis of microbial biofilm communities. bioRxiv 2019:735423. doi: 10.1101/735423

Hedblom, M. L., and Adler, J. (1980). Genetic and biochemical properties of Escherichia coli mutants with defects in serine chemotaxis. J. Bacteriol. 144, 1048-1060. 
Henry, J. T., and Crosson, S. (2011). Ligand-binding PAS domains in a genomic, cellular, and structural context. Annu. Rev. Microbiol. 65, 261-286. doi: 10.1146/ annurev-micro-121809-151631

Huntley, M. E., Nordhausen, W., and Lopez, M. D. G. (1994). Elemental composition, metabolic activity and growth of Antarctic krill Euphausia superba during winter. Mar. Ecol. Prog. Ser. 107, 23-40. doi: 10.3354/meps107023

Iwamoto, S., Nakagaito, A. N., and Yano, H. (2007). Nano-fibrillation of pulp fibers for the processing of transparent nanocomposites. Appl. Phys. 89, 461-466. doi: 10.1007/s00339-007-4175-6

Jain, S., and Pillai, J. (2017). Bacterial membrane vesicles as novel nanosystems for drug delivery. Int. J. Nanomed. 12, 6329-6341. doi: 10.2147/IJN.S13 7368

Jardas, I., Šantić, M., and Pallaoro, A. (2004). Diet composition and feeding intensity of horse mackerel, Trachurus trachurus (Osteichthyes: Carangidae) in the eastern Adriatic. Mar. Biol. 144, 1051-1056. doi: 10.1007/s00227-0031281-7

Kamasaka, K., Kawamoto, J., Chen, C., Yokoyama, F., Imai, T., Ogawa, T., et al. (2020). Genetic characterization and functional implications of the gene cluster for selective protein transport to extracellular membrane vesicles of Shewanella vesiculosa HM13. Biochem. Biophys. Res. Commun. 526, 525-531. doi: 10.1016/ j.bbrc.2020.03.125

Kawano, K., Yokoyama, F., Kawamoto, J., Ogawa, T., Kurihara, T., and Futaki, S. (2020). Development of a simple and rapid method for in situ vesicle detection in cultured media. J. Mol. Biol. 432, 5876-5888. doi: 10.1016/j.jmb.2020.09.009

Kolmakova, A., and Kolmakov, V. (2019). Amino acid composition of green microalgae and diatoms, cyanobacteria, and zooplankton. Inland Water Biol. 12, 452-461. doi: 10.1134/s1995082919040060

Manning, A. J., and Kuehn, M. J. (2011). Contribution of bacterial outer membrane vesicles to innate bacterial defense. BMC Microbiol. 11:258. doi: 10.1186/14712180-11-258

McBroom, A. J., and Kuehn, M. J. (2006). Release of outer membrane vesicles by Gram-negative bacteria is a novel envelope stress response: outer membrane vesicles relieve envelope stress. Mol. Microbiol. 63, 545-558. doi: 10.1111/j. 1365-2958.2006.05522.x

Moreira, R. N., Dressaire, C., Barahona, S., Galego, L., Kaever, V., Jenal, U., et al. (2017). BolA is required for the accurate regulation of c-di-GMP, a central player in biofilm formation. mBio 8, 443-417e. doi: 10.1128/mbio.00443-17

Morgan, R., Kohn, S., Hwang, S.-H., Hassett, D. J., and Sauer, K. (2006). $\mathrm{BdlA}$, a chemotaxis regulator essential for biofilm dispersion in Pseudomonas aeruginosa. J. Bacteriol. 188, 7335-7343. doi: 10.1128/jb.00599-06

Nagakubo, T., Nomura, N., and Toyofuku, M. (2020). Cracking open bacterial membrane vesicles. Front. Microbiol. 10:3026. doi: 10.3389/fmicb.2019.03026

Orench-Rivera, N., and Kuehn, M. J. (2016). Environmentally controlled bacterial vesicle-mediated export. Cell Microbiol. 18, 1525-1536. doi: 10.1111/cmi.12676

Papa, R., Glagla, S., Danchin, A., Schweder, T., Marino, G., and Duilio, A. (2006). Proteomic identification of a two-component regulatory system in Pseudoalteromonas haloplanktis TAC125. Extremophiles 10, 483-491. doi: 10. 1007/s00792-006-0525-0

Park, J., Kawamoto, J., Esaki, N., and Kurihara, T. (2012). Identification of cold-inducible inner membrane proteins of the psychrotrophic bacterium, Shewanella livingstonensis Ac10, by proteomic analysis. Extremophiles 16:227. doi: 10.1007/s00792-011-0422-z

Pereira, F. C., and Berry, D. (2017). Microbial nutrient niches in the gut. Environ. Microbiol. 19, 1366-1378. doi: 10.1111/1462-2920.13659

Pérez-Cruz, C., Cañas, M.-A., Giménez, R., Badia, J., Mercade, E., Baldomà, L., et al. (2016). Membrane vesicles released by a hypervesiculating Escherichia coli Nissle 1917 tolR mutant are highly heterogeneous and show reduced capacity for epithelial cell interaction and entry. PLoS One 11:e0169186. doi: 10.1371/ journal.pone.0169186

Pérez-Cruz, C., Carrión, O., Delgado, L., Martinez, G., López-Iglesias, C., Mercade, E., et al. (2013). New type of outer membrane vesicle produced by the Gramnegative bacterium Shewanella vesiculosa $\mathrm{M}^{\mathrm{T}}$ : implications for DNA content. Appl. Environ. Microbiol. 79:1874. doi: 10.1128/AEM.03657-12

Pérez-Cruz, C., Delgado, L., López-Iglesias, C., and Mercade, E. (2015). Outer-inner membrane vesicles naturally secreted by Gram-negative pathogenic bacteria. PLoS One 10:e0116896. doi: 10.1371/journal.pone.011 6896
Petrova, O. E., and Sauer, K. (2012). PAS domain residues and prosthetic group involved in BdlA-dependent dispersion response by Pseudomonas aeruginosa biofilms. J. Bacteriol. 194, 5817-5828. doi: 10.1128/jb.00780-12

Rath, A., and Deber, C. M. (2013). Correction factors for membrane protein molecular weight readouts on sodium dodecyl sulfate-polyacrylamide gel electrophoresis. Anal. Biochem. 434, 67-72. doi: 10.1016/j.ab.2012. 11.007

Rath, A., Glibowicka, M., Nadeau, V. G., Chen, G., and Deber, C. M. (2009). Detergent binding explains anomalous SDS-PAGE migration of membrane proteins. Proc. Natl. Acad. Sci. U S A. 106, 1760-1765. doi: 10.1073/pnas. 0813167106

Rossi, E., Paroni, M., and Landini, P. (2018). Biofilm and motility in response to environmental and host-related signals in Gram negative opportunistic pathogens. J. Appl. Microbiol. 125, 1587-1602. doi: 10.1111/jam.14089

Sabaeifard, P., Abdi-Ali, A., Gamazo, C., Irache, J. M., and Soudi, M. R. (2017). Improved effect of amikacin-loaded poly(D,L-lactide-co-glycolide) nanoparticles against planktonic and biofilm cells of Pseudomonas aeruginosa. J. Med. Microbiol. 66, 137-148. doi: 10.1099/jmm.0.000430

Schwechheimer, C., and Kuehn, M. J. (2015). Outer-membrane vesicles from Gram-negative bacteria: biogenesis and functions. Nat. Rev. Microbiol. 13, 605-619. doi: 10.1038/nrmicro3525

Seifert, G. J. (2018). Fascinating fasciclins: a surprisingly widespread family of proteins that mediate interactions between the cell exterior and the cell surface. Int. J. Mol. Sci. 19:1628. doi: 10.3390/ijms19061628

Sievers, F., Wilm, A., Dineen, D., Gibson, T. J., Karplus, K., Li, W., et al. (2011). Fast, scalable generation of high-quality protein multiple sequence alignments using Clustal Omega. Mol. Syst. Biol. 7:539. doi: 10.1038/msb.2011.75

Simon, R., Priefer, U., and Pühler, A. (1983). A broad host range mobilization system for in vivo genetic engineering: transposon mutagenesis in Gram negative bacteria. Bio/Technology 1, 784-791. doi: 10.1038/nbt1183-784

Söding, J., Biegert, A., and Lupas, A. N. (2005). The HHpred interactive server for protein homology detection and structure prediction. Nucleic Acids Res. 33, 244-248. doi: 10.1093/nar/gki408

Springer, M. S., Goy, M. F., and Adler, J. (1977). Sensory transduction in Escherichia coli: two complementary pathways of information processing that involve methylated proteins. Proc. Natl. Acad. Sci. U S A. 74, 3312-3316. doi: 10.1073/ pnas.74.8.3312

Tan, K., Li, R., Huang, X., and Liu, Q. (2018). Outer membrane vesicles: current status and future direction of these novel vaccine adjuvants. Front. Microbiol. 9:783. doi: 10.3389/fmicb.2018.00783

Thormann, K. M., Duttler, S., Saville, R. M., Hyodo, M., Shukla, S., Hayakawa, Y., et al. (2006). Control of formation and cellular detachment from Shewanella oneidensis MR-1 biofilms by cyclic di-GMP. J. Bacteriol. 188, 2681-2691. doi: 10.1128/jb.188.7.2681-2691.2006

Thormann, K. M., Saville, R. M., Shukla, S., Pelletier, D. A., and Spormann, A. M. (2004). Initial phases of biofilm formation in Shewanella oneidensis MR-1. J. Bacteriol. 186, 8096-8104. doi: 10.1128/jb.186.23.8096-8104.2004

Toyofuku, M., Tashiro, Y., Hasegawa, Y., Kurosawa, M., and Nomura, N. (2015). Bacterial membrane vesicles, an overlooked environmental colloid: biology, environmental perspectives and applications. Adv. Colloid Interface Sci. 226, 65-77. doi: 10.1016/j.cis.2015.08.013

Toyotake, Y., Cho, H.-N., Kawamoto, J., and Kurihara, T. (2018). A novel 1acyl-sn-glycerol-3-phosphate $O$-acyltransferase homolog for the synthesis of membrane phospholipids with a branched-chain fatty acyl group in Shewanella livingstonensis Ac10. Biochem. Biophys. Res. Commun. 500, 704-709. doi: 10. 1016/j.bbrc.2018.04.140

Tsuji, T., Ozasa, H., Aoki, W., Aburaya, S., Funazo, T. Y., Furugaki, K., et al. (2020). YAP1 mediates survival of ALK-rearranged lung cancer cells treated with alectinib via pro-apoptotic protein regulation. Nat. Commun. 11:74. doi: 10.1038/s41467-019-13771-5

Turnbull, L., Toyofuku, M., Hynen, A. L., Kurosawa, M., Pessi, G., Petty, N. K., et al. (2016). Explosive cell lysis as a mechanism for the biogenesis of bacterial membrane vesicles and biofilms. Nat. Commun. 7:11220. doi: 10.1038/ ncomms 11220

Ud-Din, A. I. M. S., and Roujeinikova, A. (2017). Methyl-accepting chemotaxis proteins: a core sensing element in prokaryotes and archaea. Cell Mol. Life Sci. 74, 3293-3303. doi: 10.1007/s00018-017-2514-0 
Wadhams, G. H., and Armitage, J. P. (2004). Making sense of it all: bacterial chemotaxis. Nat. Rev. Mol. Cell Bio. 5, 1024-1037. doi: 10.1038/nrm1524

Yokoyama, F., Kawamoto, J., Imai, T., and Kurihara, T. (2017). Characterization of extracellular membrane vesicles of an Antarctic bacterium, Shewanella livingstonensis Ac10, and their enhanced production by alteration of phospholipid composition. Extremophiles 21, 723-731. doi: 10.1007/s00792017-0937-z

Yu, N. Y., Wagner, J. R., Laird, M. R., Melli, G., Rey, S., Lo, R., et al. (2010). PSORTb 3.0: improved protein subcellular localization prediction with refined localization subcategories and predictive capabilities for all prokaryotes. Bioinformatics 26, 1608-1615. doi: 10.1093/bioinformatics/btq249
Conflict of Interest: The authors declare that the research was conducted in the absence of any commercial or financial relationships that could be construed as a potential conflict of interest.

Copyright (c) 2021 Yokoyama, Imai, Aoki, Ueda, Kawamoto and Kurihara. This is an open-access article distributed under the terms of the Creative Commons Attribution License (CC BY). The use, distribution or reproduction in other forums is permitted, provided the original author(s) and the copyright owner(s) are credited and that the original publication in this journal is cited, in accordance with accepted academic practice. No use, distribution or reproduction is permitted which does not comply with these terms. 